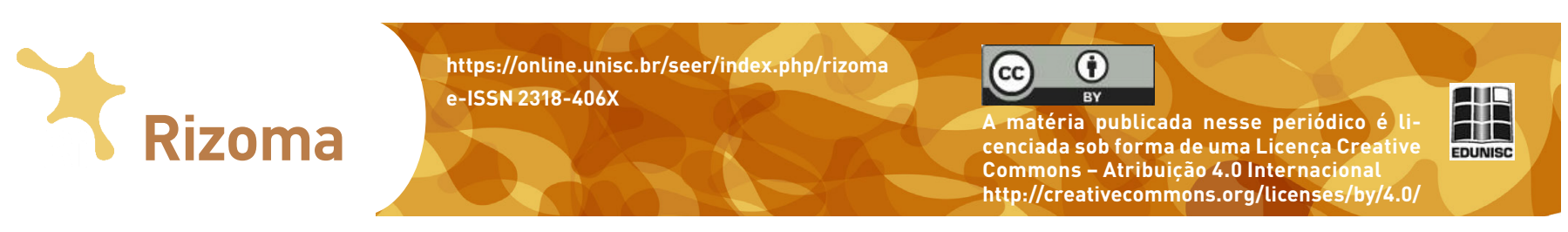

Resenha 0

\title{
Para a prática do jornalismo ambiental
}

Resumo: Resenha do livro Jornalismo Ambiental: teoria e prática, organizado pelos pesquisadores Ilza Maria Tourinho Girardi, Cláudia Herte de Moraes, Eloisa Beling Loose e Roberto Villar Belmonte. Este livro é o resultado do trabalho, de anos de pesquisas e debates em congressos, sobre o tema do Grupo de Pesquisa Jornalismo Ambiental da Universidade Federal do Rio Grande do Sul, contribuindo para o ensino e a prática do jornalismo ambiental com um material didático acessível digitalmente. $\mathrm{O}$ livro é uma contribuição às proposições das Novas Diretrizes Curriculares de Jornalismo que estabeleceram, entre as competências do jornalista em formação, a compreensão e valorização das conquistas históricas da cidadania, ainda em risco, como o desenvolvimento sustentável. Os organizadores reuniram em 11 capítulos diversos pontos de vistas sobre teorias e práticas do jornalismo ambiental com o objetivo de mostrar a centralidade das problemáticas socioambientais no mundo moderno e o papel do jornalista neste contexto.

Palavras chave: Jornalismo ambiental. DCNs Jornalismo. Problemas socioambientais. Crise ambiental.

O mundo tem vivenciado há algumas décadas grandes mudanças ambientais globais e uma diversidade de problemas socioambientais como mudanças climáticas, diminuição da camada de ozônio, redução da biodiversidade terrestre e marítima, poluição e catástrofes ambientais. Estes problemas têm chamado a atenção para a crise ambiental como um fenômeno na Era Moderna. Desde a década de 1960, o jornalismo tem desempenhado um papel importante ao levar, ao grande público, o conhecimento desses problemas. A visibilidade dessas problemáticas ambientais através do jornalismo foi central na fomentação das discussões, dos debates, das atitudes e das propostas políticas que se sucederam ao longo deste período até aos dias atuais. Demonstrando sua clara importância no agendamento de eventos e acontecimentos na agenda pública sobre a crise ambiental (McCombs, 2010).

A visibilidade da questão socioambiental na atualidade se deve, em grande parte, ao que o jornalismo publicizou nas diversas mídias, ao longo das décadas, tanto sobre as catástrofes ambientais,
Noêmia Félix da Silva'

${ }^{1}$ Jornalista e professora de Jornalismo, Ciência e Meio Ambiente, na Escola de Comunicação da Pontifícia Universidade Católica de Goiás, com tese de doutorado sobre Jornalismo e Desenvolvimento Sustentável, pelo Programa de Pós-graduação em Comunicação da Faculdade de Comunicação, da Universidade de Brasília (UnB).

Universidade na qual também fez seu mestrado em Comunicação, especialista em História pela Universidade Federal de Goiás (UFG), e bacharel em Jornalismo também por esta universidade. E-mail: noemiafelix@terra.com.br. 


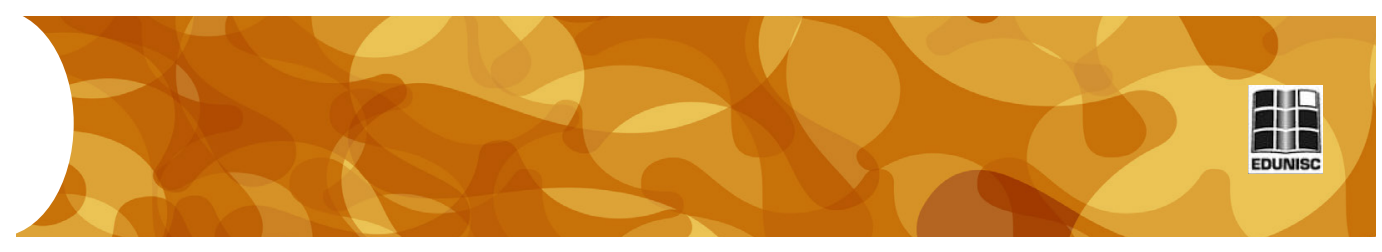

como também sobre os riscos desses eventos à vida e à saúde humana, levando à população a cobrar dos governantes políticas públicas e resoluções para esta crise ambiental. Diante deste quadro mundial, uma obra sobre jornalismo ambiental, reflexões teóricas e práticas é fundamental para ajudar no processo de formação de novos jornalistas para que possam enfrentar esta temática complexa e tão necessária no cotidiano da população.

O livro Jornalismo ambiental: teoria e prática foi organizado pelos pesquisadores de Grupo de Pesquisa Jornalismo Ambiental da Universidade Federal do Rio Grande do Sul e por convidados que compartilharam suas vivências com a prática do jornalismo ambiental. O resultado é uma obra que traz no seu cerne a preocupação de elaboração de um livro didático que contribua com o preparo dos futuros jornalistas, a partir da proposta das Novas Diretrizes Curriculares de Jornalismo, estabelecidas em 2013, e estão em plena implantação nos cursos de Jornalismo pelo Brasil. O livro procura ser o mais acessível possível, sendo disponibilizado em formato e-book, distribuído gratuitamente na internet aos interessados no tema de todo Brasil e do mundo.

As novas DCNs estabeleceram que, entre as competências do jornalista em formação, é preciso compreender e valorizar as conquistas históricas da cidadania, ainda em risco, como o desenvolvimento sustentável. Esse item está explicito no documento deste modo porque as questões e as problemáticas ambientais ainda precisam ser implementadas e correm o risco de não se concretizarem, pelo não comprometimento das nações desenvolvidas com acordos e políticas públicas globais que as coloquem em prática.

Nessa obra, os organizadores reuniram em 11 capítulos diversos pontos de vistas sobre teorias e práticas do jornalismo ambiental com o objetivo de mostrar a centralidade das problemáticas socioambientais no mundo moderno e o papel do jornalista neste contexto. Este livro é o resultado de dez anos de discussões, pesquisas e debates sobre o jornalismo e sua interrelação com o meio ambiente, tendo como bases fundamentais, a pluralidade de vozes no jornalismo e de uma visão mais complexa sobre as problemáticas socioambientais contemporâneas, com uma abordagem comprometida com a sustentabilidade e as práticas sustentáveis, ou seja, uma mudança comportamental.

Logo no prefácio do livro, escrito pelo pesquisador do jornalismo, que integrou a Comissão de Especialistas que redigiu as Diretrizes Curriculares Nacionais para os Cursos de Jornalismo, Eduardo Meditsch ressalta a importância da obra para o ensino do jornalismo, pois lembra a "exigência da centralidade da consciência ambiental" no nosso mundo contemporâneo, de modo que estamos esgotando nossos recursos naturais, impactando na redução drástica da 


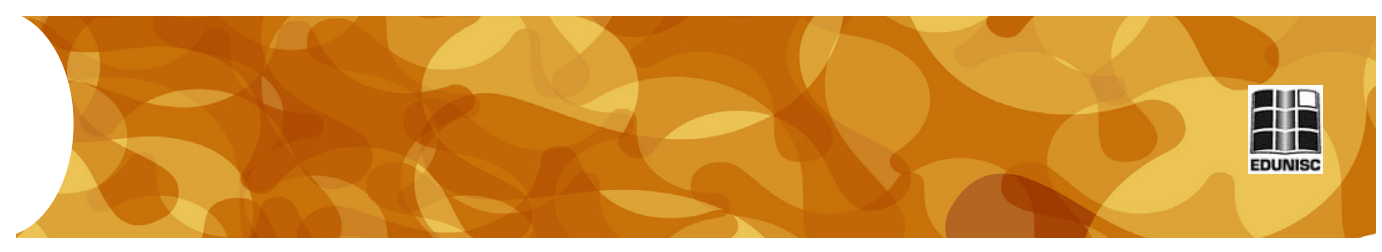

fauna e da flora, assim como da biodiversidade planetária, e colocando em risco o a vida do e no planeta.

Meditsch deixa claro que a proposta da discussão ambiental nas diretrizes de jornalismo não é criar uma especialização numa única disciplina que dê conta de uma discussão tão complexa como é a ambiental, e sim, que a proposta do livro é a de que o jornalismo ambiental seja um novo paradigma que companha a formação geral de todo futuro jornalista, por entender o jornalista numa dimensão intelectual, dando conta da complexidade de mundo, também numa dimensão educativa e da "Ética do Cuidado". A ética do cuidado foi discutido por Heidegger, sob influência da filosofia de Søren Kierkegaard, em um nível abstrato e ontológico, para descrever algo básico no ser humano. Para Heidegger, o "cuidado solicitude" (fürgsorge) tem como definição o interesse pelo planeta Terra e pela humanidade, demonstrando deste modo as potencialidades humanas, para além da angustia da luta pela subsistência cotidiana, ou seja, do "cuidado angústia" (sorge). Deste modo, a "Ética do Cuidado" está centrada no valor do cuidado do próprio ser humano e do Planeta Terra.

$\mathrm{Na}$ apresentação do livro, o grupo de organizadores deixa claro que diante do desafio de incorporar o debate do jornalismo ambiental proposto pelas DCNs, procurou-se ampliar o debate e, ao mesmo tempo, trazer um livro didático, de fácil leitura, voltado para os alunos da graduação. O livro não foi organizado de modo a ficar restrito apenas à fundamentação teórica existente da área, mas ir além e propor práticas, em forma de exercícios aos alunos, e leituras complementares sobre os temas ali discutidos.

O livro é aberto com o capítulo escrito pela pesquisadora e uma das pioneiras na discussão sobre jornalismo ambiental no Brasil, Ilza Maria Tourinho Girardi, que narra a criação da primeira disciplina de jornalismo ambiental, na Faculdade de Biblioteconomia e Comunicação (FABICO/UFRS), em 2004. No capítulo, Ilza Girardi defende a importância das disciplinas de jornalismo ambiental nas universidades como importante ferramenta de educação ambiental dos jornalistas para, posterior, educação da população para o desenvolvimento da capacidade de participar e decidir dentro de uma "cidadania planetária". Dentro de uma lógica de engajamento, a autora desenvolve um conceito de jornalismo ambiental caracterizado por

mostrar uma visão sistêmica dos fatos; dar conta da complexidade dos eventos ambientais; contemplar a diversidade dos saberes e não ser refém de fontes oficiais; defender a biodiversidade e a vida em sua plenitude, o que significa deixar de ser imparcial; assumir seu papel educativo, cidadão e transformador. (GIRARDI, 2018, p. 19-20) 


\section{$\gamma_{\text {Rizoma }}$}

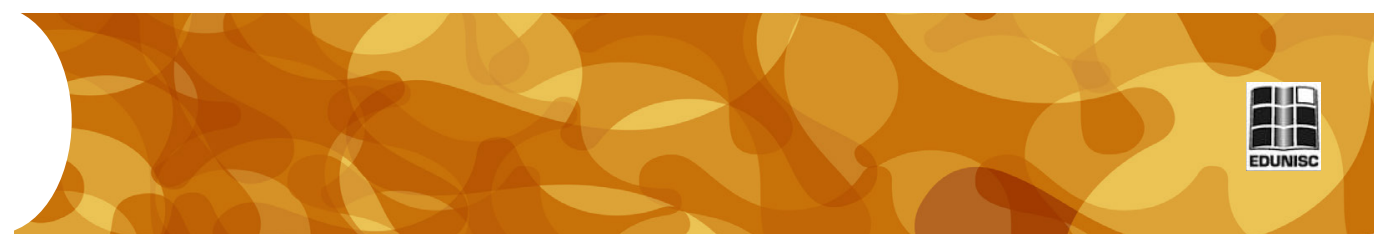

Este capítulo é uma reflexão importante e compõe a história das pesquisas e discussões do jornalismo ambiental no Brasil.

O segundo capítulo trata dos processos de "ensinagem" do jornalismo ambiental. Escrito pelas pesquisadoras Augusta Gern e Myrian Del Vecchio de Lima que defendem a necessidade dos estudantes de jornalismo compreenderem o conceito de meio ambiente, como sendo mais do que ecologia e natureza e, sim, como um campo complexo que deve transpassar todas as áreas do conhecimento. E sugerem que esse ensino pode ser realizado tanto dentro de uma disciplina específica do tema, como também de modo transversal, em diversas outras disciplinas da matriz curricular do curso, mas sempre tendo em vista um olhar sistêmico de meio ambiente.

Tema também abordado no capítulo seguinte do pesquisador Eduardo Geraque que há 13 anos trabalha na redação da Folha de $S$. Paulo, na cobertura de meio ambiente, ciência, tecnologia, cidades e políticas públicas. No texto, o jornalista narra não só a sua experiência na cobertura ambiental como também aponta possíveis caminhos para se lidar com a cobertura ambiental nos jornais brasileiros, seus desafios e soluções. Ele ressalta a importância da pauta nascer transversal e relacionar as discussões de especialistas e ambientalistas como atores sociais. Este olhar transversal deve ser, segundo ele, treinado diariamente pelo jornalista, num exercício constante para buscar entender como funcionam as várias dimensões de um tema ambiental, sejam elas culturais, políticas, econômicas, tecnológicas, entre outras. E é categórico em afirmar que, os jornalistas precisam "jogar o jogo" nas redações, e ao mesmo tempo, enfrentar o desafio de sair de abordagens superficiais e aprofundar no tema, "sob pena de fazer um jornalismo sem interesse social".

A importância das bases do jornalismo ambiental na produção das pautas jornalísticas é retratada, nos três capítulos seguintes. As autoras Cláudia Herte de Moraes e Eliege Maria Fante abordam a importância de se saber no que consiste a sustentabilidade e como esse conceito é central para se construir uma pauta que dê conta da complexidade ambiental. E o formato mais adequado para abordar o pensamento socioambiental é a reportagem ampliada, apontada por Reges Schwaab como o espaço que possibilita a exposição das diversas facetas destas problemáticas. E as políticas públicas ambientais são apontadas pelas autoras Eliege Fante e Cláudia Herte de Moraes como um lugar privilegiado para a busca de pautas e fontes essenciais para a compreensão das decisões políticas sobre o meio ambiente e devem ser valorizadas no jornalismo.

E como não poderia deixar de ser, o tema das mudanças climáticas, um dos mais importantes e sérios na contemporaneidade foi abordado no livro. As autoras Eloisa Beling Loose e Cláudia Herte 


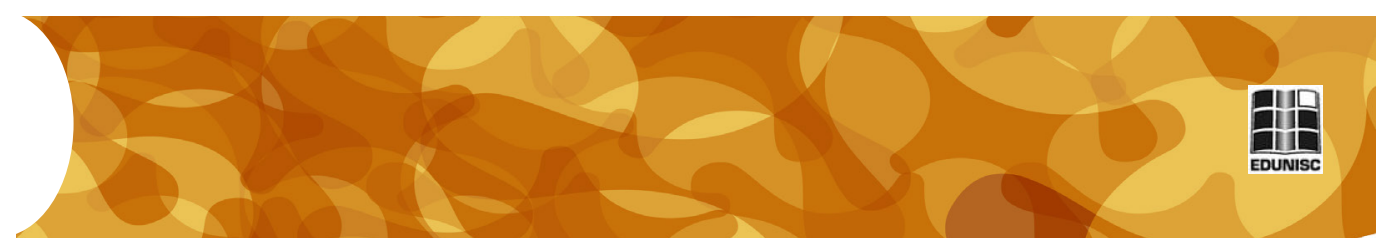

de Moraes discutem as mudanças do clima procurando mostrar as diferentes formas de enfrentamento do problema, seja pela mitigação para a redução das emissões dos gases de efeito estufa, ou seja, pela as adaptações necessárias a serem realizadas para lidar com os problemas climáticos cada vez mais frequentes. No final do capítulo, as autoras propõem estratégias para uma melhor cobertura sobre este tema tão complexo e importante no mundo atual.

Os conflitos ambientais é um lugar interessante para se perceber as estratégias de poder-saber que envolvem a questão ambiental. Deste modo, a jornalista e socióloga Ângela Camana traz o resultado de uma pesquisa sobre conflitos ambientais brasileiros, apresentando as abordagens sobre o tema e sobre a justiça ambiental, tendo como exemplo analisado, a situação conflituosa da Amazônia, que envolve a questão fundiária e grandes projetos desenvolvimentistas.

Hoje é essencial abordar a questão ambiental nas cidades, afinal os veículos urbanos a base de combustíveis fósseis são os maiores emissores de gases de efeito estufa no ambiente, e grande parte dos problemas estão relacionados ao grande número populacional. As cidades são um lugar importante para se discutir os problemas ambientais, mostrando ao homem os impactos que o seu modo de viver tem no meio ambiente. Procurando mostrar as conexões sobre a questão ambiental e as cidades, Débora Gallas e Eutalita Bezerra mostram como diversos temas sociais podem ser abordados pelos jornalistas, como a ocupação desordenada das cidades, o modelo rodoviário de transporte baseado em veículos para mostrar modelos alternativos sustentáveis.

E por fim, os dois últimos capítulos discutem a importância da fotografia e do jornalismo de dados para o jornalismo ambiental. A jornalista Sinara Sandri, mostra o poder da fotografia e como ela pode contribuir para a construção de narrativas coerentes dentro de um mundo caótico, para o jornalismo ambiental, mostrando suas potencialidades na "abordagem sistêmica na identificação de situações e alternativas justas e éticas em casos onde os conflitos sociais e ambientais tomam contorno de violação de direitos humanos".

O jornalista e professor Marcelo Träsel traz um case sobre a utilização dos bancos de dados públicos na produção do jornalismo ambiental. Ele se baseia numa técnica de trabalho investigativo quem vem crescendo no Brasil, o Jornalismo Guiado por Dados (JGD). Esta abordagem jornalística assistida por computador (RAC) tem no uso de dados, a principal fonte de informação para a produção de notícias, como as técnicas de reportagem visualização de dados, infografia, criação e manutenção de bases de dados e a política de acesso à informação e transparência pública de governos. 


\section{Rizoma}

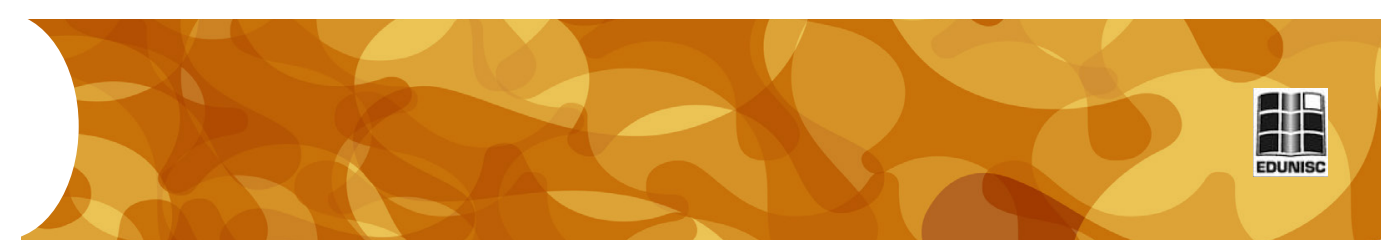

Após esta breve descrição da obra, é importante destacar as múltiplas dimensões da abordagem dada pelos autores sobre o jornalismo ambiental e das diversas formas de aborda-lo na produção de um trabalho jornalístico de qualidade. O objetivo dos autores foi trazer um livro para os cursos de jornalismo no Brasil que possibilitasse fazer discussões teóricas sobre o tema ambiental, mas acima de tudo, apontar experiências práticas para que professores e alunos se exercitem na abordagem e na produção jornalística sobre o jornalismo ambiental, problemática fundamental no mundo moderno. 